\title{
NERUDA Y LA POÉTICA DE LAS COSAS: REFLEXIONES SOBRE MODERNIDAD Y POSMODERNIDAD
}

POR

\author{
Renato MartíneZ \\ Cornell College, Iowa
}

\section{El MUNDO DE LAS COSAS Y LAS COSAS DEL MUNDO}

A principios de 1990, la Fundación Pablo Neruda abrió la casa del poeta en Isla Negra como museo. Un mundo extraordinario de toda suerte de objetos se presentó frente a los ojos atónitos del público. Desde exóticas conchas marinas - tema en que el vate era un verdadero experto- hasta rarísimos libros de anticuario; desde mascarones de proa hasta juguetes; desde botellas de vidrio pigmentado hasta piedras con los diversos acentos del arco iris mineral; todo estaba allí: colores, texturas, formas. En ese momento quedó claro para muchos observadores que el interés de Neruda en la madera, la cebolla, el tomate y la luna en el mar, todos temas de las Odas (1954-57), eran además de un motivo en su vasta poética, una parte importante de su vida diaria. La atención al mundo material aparece en la poesía nerudiana - aunque asociada a una angustia metafísica - ya en las Residencias (1925-45), pero habría de esperarse hasta las Odas para su expresión materialista -ya más definitiva.

La exigua crítica dedicada a las Odas suele situar al poeta y sus textos en un axis vertical, donde el primero eleva la humilde existencia de las cosas ordinarias al nivel refinado de lo poético; o bien, donde el vate - en un gesto anti-intelectualista - canta para las masas, haciendo descender lo poético del alto pedestal de las bellas letras, hasta el suelo diario de lo cotidiano. La presente nota, por el contrario, intenta mostrar que la relación de Neruda y las cosas es más bien horizontal; más bien metonímica que metafórica. A través de una poética de las cosas, ${ }^{1}$ Neruda fue ilustrando la situación de continuidad que existe entre el ser humano y su mundo, es decir, las Odas representan un proyecto heurístico donde Neruda afirma una vez más que "la vida no está determinada por la conciencia, sino la conciencia por la vida". Objetos de arte, mercancías, herramientas, comida, son el engrudo de la sociedad moderna; son los signos e íconos de nuestra malla discursiva. Son, además, una expresión de valor que nos permite tomar posición en una clase y en un género socialmente definidos. ¿Es esto algo nuevo? No, en absoluto. Ya en

\footnotetext{
' Karl Marx and Frederick Engels, The German Ideology (New York: International Publishers, 1977) 47. La traducción es mía.
} 
1867 Marx había propuesto que existe una relación fundamental entre valor y mercancía, entre producción y representación: "El valor, por lo tanto, no se pasea con un letrero describiendo lo que es. En cambio, es el valor lo que convierte a cada producto en un jeroglífico social ... porque estampar un objeto de uno como valor es un producto social tanto como lo es el lenguaje". ${ }^{2}$ En estudios recientes - y no tan recientes-sobre teoría de representación, la relación cosa-significado ha experimentado una esmerada atención. Tal vez el trabajo más provocativo en esta línea de indagación haya sido el de Deleuze y Guattari - Anti-Oedipus - en que estudian toda empresa humana como resultado de producción y deseo. ${ }^{3}$

Han pasado ya cuarenta años desde la publicación de las Odas elementales y sin duda el mundo habitado por los objetos de las Odas ha cambiado. E1 propio poeta nunca podía haber predicho la disolución de la Unión Soviética ni el tránsito del orbe socialista hacia un futuro por ahora incierto. El pensamiento contemporáneo, por otro lado, parece moldearse por un nuevo universo ideológico: el del posmodernismo. Sin embargo, desde la posición privilegiada del futuro y la teleología ya realizada del proyecto nerudiano, se puede apreciar cuán acertado era el camino epistemológico tomado por el poeta. Este trabajo intenta probar, adicionalmente, que el vínculo objeto-conciencia, aspecto central de la poética de las cosas, permite, hoy como ayer, un acusado entendimiento de las relaciones humanas y del estado de conciencia que avala determinadas producciones culturales.

El posmodernismo - no nos referimos a la superación de la estética de Darío, como se verá- ha sido definido por Jean-François Lyotard en La Condition postmoderne: Rapport sur le savoir (1979) ${ }^{4}$ como una condición del conocimiento en que se duda de las metanarrativas. Por modernismo, a su vez, designa "cualquier ciencia que se legitimiza a sí misma con referencia a un metadiscurso que apele explícitamente a una gran narrativa, tal como la dialéctica del Espíritu, la hermenéutica del significado, la emancipación de lo racional o del sujeto trabajador, o la creación de riqueza" (xxiii). En esta perspectiva, no cabe duda de que la obra de Neruda en general y las Odas en particular constituyen un proyecto modernista en que el grand récit es la emancipación humana, dirigida por el sujeto trabajador a través de la revolución proletaria. La siguiente pregunta debe necesariamente abordarse a continuación: ¿Es posible hablar de conciencia de sociedad postindustrial más allá de la frontera del mundo industrializado, en la llamada "periferia"? Sin duda, el tema de la posmodernidad latinoamericana es controversial y una discusión extensa de sus posibilidades reales escapa los límites del presente trabajo. George Yúdice ha sugerido - en forma muy acertada, por lo demás - que la comprensión de la posmodernidad de Latinoamérica debe pasar por una desconstrucción del modelo europeo-

\footnotetext{
${ }^{2}$ Karl Marx,The Capital (Moscow: International Publishers, 1971) 79. La traducción es mía.

${ }^{3}$ Gilles Deleuze and Félix Guattari, Anti-Oedipus (Minneapolis: University of Minnesota Press, 1986).

${ }^{4}$ Jean-François Lyotard, The Postmodern Condition: A Report on Knowledge (Minneapolis: University of Minnesota Press, 1989). La primera edición, en francés data de 1979. La traducción de este párrafo es mía.
} 
norteamericano, seguida de una reconstrucción guiada por el contexto de Latinoamérica. ${ }^{5}$ En cualquier caso, el modernismo de Neruda se hace evidente al ser contrastada su poesía con productos culturales más recientes y poéticas de tipo rupturista —de Oscar Hahn y Nicanor Parra, por ejemplo. Éstas, contra el viento y la marea de las definiciones, muestran su separación de la gran narrativa de la modernidad.

II. Acerca DE ZAPatos Viejos Y NUEVos

El siguiente es el texto de "Oda a pies de fuego", de Nuevas odas elementales (1956):6

\begin{tabular}{ll} 
Con esos & que adelantas al viento. \\
pies & Antes \\
pequeños & de que \\
parecidos & te llame \\
a abejas, & ya has llegado, \\
cómo & y junto a la agresiva \\
gastas & cintura de la costa, \\
zapatos! & arena, piedra, espinas, \\
Yo sé & vas \\
que vas y vienes, & a mi lado, \\
en los bosques & \\
pisando troncos, mudas & dos informes \\
aguas verdes & pepinos, \\
o en las calles & dos batracios \\
andando & de cuero \\
intransitables & desteñido, \\
suburbios, pavimentos & eso, \\
de alquitrán fatigado, & eso \\
a esa hora & han llegado \\
en que la luz & a ser \\
del mundo & los dos luceros \\
se deshilacha como & hace un mes, sólo un mes \\
una bandera, & salidos \\
tú, por calles y bosques, & de la zapateria. \\
a mi lado & \\
caminas, & Como \\
bravía, inagotable & flor amarilla de hermosura, \\
compañera, & abierta en la barranca, \\
\hline
\end{tabular}

\footnotetext{
${ }^{5}$ George Yúdice, "Postmodernity and the Transnational Capitalism in Latin America", On Edge editado por George Yúdice, Jean Franco and Juan Flores (Minneapolis: University of Minnesota Press, 1992).

${ }^{6}$ Todos los textos de las Odas de Neruda están tomados de Libro de las Odas (Buenos Aires: Editorial Losada S.A., 1972).
} 




Esta oda, pese a su formalidad de liviano humorismo, es un poema de amor en que la voz poética se dirige a su "bravía, inagotable/compañera/" con la familiaridad que caracteriza a la función conativa de todas las odas. Entre los versos 1 al 45, el poema aparece marcado semánticamente por la propiedad de "actividad incesante" de la receptora del mensaje poético. Una actividad que se despliega en armonía con las cosas del mundo, "en los bosques/ pisando troncos, mudas/ aguas verdes/o en las calles/ andando/ intransitables/ suburbios, pavimentos ..." Desde el verso 46, la voz poética vuelca su atención sobre los zapatos. La narración se ocupa ahora de la metamorfosis producida por el uso desde que "salieron/ bruñidos/ como dos/ pequeñas herramientas/ de combate,/intactos ..." hasta "y hoy/ que veo?/ En tus pies/ dos erizos/ arrugados, dos puños entreabiertos ..."

La relación de armonía existente entre persona y cosa - que es "herramienta" y al mismo tiempo "dos luceros"- explica la continuidad que Neruda ve entre humanidad y naturaleza. La comunión de estos elementos va segregando a la vez las aventurosas andanzas de la amada y sus zapatos, que, junto a la voz poética, van recorriendo las calles y los bosques. Esta aventura de dos personas que se aman no es otra cosa sino la expresión de un hipotexto - un grand récit del proyecto modernista- en que dos seres reales, vinculados por los lazos del más íntimo pacto, el del amor y la solidaridad, se proyectan en la lucha diaria y en la alegría cotidiana de vivir en un mundo tan concreto y material como el nuestro. 
La armonía entre las personas y los elementos de la naturaleza desaparece en la antipoesía de Nicanor Parra. La crítica ha sido fecunda en mostrar que Parra desacraliza el yo poético porque rechaza, en primer lugar, al poeta como "un pequeño dios" del "Non serviam" huidobriano. Desautoriza, en segundo lugar, la voz existencialmente angustiada de las primeras Residencias y la narración profundamente telúrica o reivindicativa de la producción nerudiana posterior. ${ }^{7} \mathrm{Y}$, en tercer lugar, porque evidencia un agnosticismo radical que tanto recuerda la proclama Nietzscheana de la muerte de Dios. ${ }^{8}$ Este último aspecto es el que nos interesa recalcar: las leyes que rigen el movimiento del mundo han entrado en conflicto. Sus elementos han perdido el peso específico y las cosas ya no orbitan alrededor de nuestra conciencia sino que caen, junto con nosotros. Todo vale igual, todo evento es igual a otro, ya lo dice un noticiario de 1957: "Plaga de motonetas en Santiago./ La Sagan se da vuelta en automóbil./ Terremoto en Irán: 600 víctimas./ El gobierno detiene la inflación".9

La poesía de Parra, una poesía "imperfecta, irritante, corrosiva, anticipatoria" —en el decir de Valente (Ibánez-Langlois, 9)-y que ofrecemos como contraste a continuación, muestra no sólo que el sujeto se fragmenta entre las cosas, sino que las cosas se van haciendo independientes e irrecuperables. El primer paso en esta senda es la pérdida del apelativo. Examinemos "Cambios de nombre", de la colección Versos de salón (1962):

\section{Cambios de nombre}

A los amantes de las bellas letras

Hago llegar mis mejores deseos

Voy a cambiar el nombre de algunas cosas.

Mi posición es ésta:

El poeta no cumple su palabra

Si no cambia los nombres de las cosas.

¿Con qué razón el sol

Ha de seguir llamándose sol?

¡Pido que se le llame Micifuz

El de las botas de cuarenta leguas!

¿Mis zapatos parecen ataúdes?

Sepan que desde hoy en adelante

Los zapatos se llaman ataúdes.

Comuníquese, anótese y publíquese

Que los zapatos han cambiado de nombre:

Desde ahora se llaman ataúdes.

\footnotetext{
${ }^{7}$ Ver por ejemplo el trabajo de Hugo Montes y Mario Rodríguez: Nicanor Parra y la poesía de lo cotidiano (Santiago de Chile: Editorial del Pacifico S.A., 1970).

${ }^{8}$ En el prólogo de José Miguel Ibánez-Langlois a Antipoemas (Barcelona: Seix Barral, 1976).

${ }^{9}$ Nicanor Parra, Antipoemas (Barcelona: Seix Barral, 1976). Los poemas citados están tomados de este texto.
} 


\begin{abstract}
Bueno, la noche es larga
Todo sujeto que se estime a sí mismo

Debe tener su propio diccionario

$\mathrm{Y}$ antes que se me olvide

Al propio dios hay que cambiarle nombre:

Que cada cual lo llame como quiera:

Ése es un problema personal.
\end{abstract}

Zapatos o ataúdes, ¿qué más da? "Todo sujeto que se estime a sí mismo" debe tener sus propias reglas. El poeta, que se dirige irónicamente a "los amantes de las bellas letras", y que aquí no tiene nada de genio iluminado, ni de héroe de epopeya alguna -eso quedó atrás - se adorna con los codos raídos del burócrata - "Comuníquese, anótese y publíquese". Es un antipoeta, un ángel exterminador, un agente de destrucción de este orden gastado e inútil. En el poema de Parra, los zapatos han perdido la complicidad de cosa necesaria con que la voz poética de las Odas salía a mundo, y se disgregan, en el caos inconmensurable de este mundo que ya nunca más será el mismo.

El nombre - ya lo sabemos desde Saussure - es una expresión arbitraria con la cual una comunidad socio-lingüística acuerda designar a un determinado objeto. Un cambio unilateral del nombre rompe el vínculo que existe entre cosa y sociedad y se modifica así su valor como objeto de uso y objeto de cambio. ¿Es que advertimos aquí una vinculación de la poesía de Parra con la vanguardia, es que volvemos a encontrar al "pequeño dios"? Aunque ahora no cree horizontes cuadrados ni haga florecer la rosa en el poema, ¿no parece ser que se atribuye a sí mismo plenos poderes para cambiar la lengua? Tal vez haya que responder a estas preguntas en el negativo. A juzgar por la obra de Parra en su conjunto, no se advierte en el antipoeta el triunfo delirante de la subjetividad presente en la vanguardia, sino que más bien, una duda fundamental en la validez de la empresa humana y en el éxito del proyecto reivindicativo del modernismo. El resultado de esta pérdida de certidumbre es una poesía cuya voz adquiere una expresión destemplada, sarcástica, un kitsch lírico, es decir, una vocación posmoderna avant la lettre. El consumismo y la cesantía de los setenta y los ochenta - con su respectiva cosificación del hombre y humanización del objetohabrían de confirmar la anticipación que la poesía de Parra muestra, de una realidad que se abría paso en forma inexorable.

Antes de clausurar el tema de los zapatos hemos de considerar la obra "Zapatos campesinos", la conocida pintura de Van Gogh, que ha sido señalada como un clásico del modernismo pictórico. Obra que además ha recibido una antigua atención, desde Martin Heidegger hasta Frederic Jameson, pasando por Derrida. Jameson ha hecho un contraste entre esta pintura y la obra de arte Pop de Andy Warhol titulada "Zapatos de polvo de diamante". ${ }^{10}$ Según Jameson, la verdadera naturaleza de los zapatos de Van Gogh no puede ser entendida sin tener como referente "los objetos de la miseria agrícola, de la espantosa pobreza rural y del rudimentario mundo del bestial trabajo campesino ..." (Jameson, 145). Los "Zapatos de polvo de diamante" de Andy Warhol, en cambio, y de acuerdo con el mismo autor, "ya no nos interpelan con la inmediatez del calzado de Van

${ }^{10}$ Frederic Jameson, "El posmodernismo o la lógica del capitalismo tardío", Casa de las Américas 155-56 (1986) 141. 
Gogh: de hecho, me siento tentado a afirmar que no nos interpelan en absoluto ... nos encontramos - continúa Jameson- con una colección casual de objetos muertos, que descansan en el cuadro como otros tantos nabos, tan cortados de su anterior mundo vital como un montón de zapatos abandonados en Auschwitz" (Jameson, 146). La reflexión de Jameson es similar a la que mantenemos como hipótesis en este trabajo. Aquello que Jameson llama la interpelación de los objetos y que en este trabajo designamos como la mediación de las cosas con la conciencia, muestra la diferencia fundamental entre el antipoema de Parra y la oda de Neruda y que reside, básicamente, en la particular relación de los objetos con el mundo percibido y en la situación de inmediatez - o mediatezextendida entre la cosa y la tarea humana - metonimia de la mano que la produce. Esta relación diferencial es un aspecto que tal vez separe en forma más definitiva al modernismo de la posmodernidad.

\title{
III. SOBRE SOPAS Y CALDILLOS
}

Es una feliz coincidencia que Andy Warhol haya pintado además una pintura consistente de una serie de tarros de sopas Campbell. Es evidente que el pasado como publicista del artista se hace evidente en su obra madura, para expresar, como ha dicho Jameson, "el fetichismo de la mercancía en la tránsición al capitalismo tardío" (Jameson 147). Bajo el acápite de las prosaicas sopas Campbell hemos de recordar forzosamente el poema de Óscar Hahn "El televidente", perteneciente a la segunda edición de Mal de amor (1986). El texto es el siguiente:"11

\author{
Aquí estoy otra vez de vuelta \\ en mi cuarto de lowa City \\ Tomo a sorbos mi plato de sopa Campbell \\ frente al televisor apagado \\ La pantalla refleja la imagen \\ de la cuchara entrando a mi boca \\ y soy el aviso comercial de mí mismo \\ que anuncia nada \\ a nadie
}

La temática del poema armoniza con el tono de la colección entera y que ha sido definido - por Rodríguez Padrón-como "diálogos de la ausencia", y como una expresión de la temporalidad del sentimiento amoroso. ${ }^{12}$ Waldo Rojas, por otra parte, sugiere que Hahn muestra en este libro cómo, en la exaltación de la pasión amorosa, surge "un

\footnotetext{
${ }^{11}$ Los textos de Óscar Hahn citados en este trabajo pertenecen a Tratado de sortilegios (Madrid: Ediciones Hiperión, 1992).

${ }^{12}$ Los trabajos de Jorge Rodríguez Padrón y Waldo Rojas están en en Asedios a Óscar Hahn. Pedro Lastra y Enrique Lihn, editores (Santiago de Chile: Editorial Universitaria, 1989) 35-38 y 74.
} 
sobrecogimiento de lucidez" en el cual se opera el encuentro entre la muerte y el sentimiento erótico, "Aquella dulce muerte tu hermosísimo amor". Señala además, que la "narrativa" del poemario no alude necesariamente a un desenlace amoroso que termina en quiebre, sino más bien, a la existencia en una "toponimia bipolar", siendo una de ellas el dormitorio y la otra el espacio cósmico. Habría de entenderse - según Rojas- el regreso "a mi cuarto en Iowa City" como un regreso a la "Realidad", "el gaje de la reconciliación con el mundo".

Rojas practica en este artículo una poética del espacio, que reposa más en Freud que en Bachelard y donde se enfrentan el principio de placer con el principio de Realidad con mayúscula. Parece ser una alianza hermenéutica productiva, sólo que esta muerte figurada de la voz poética, esta caída en el hastío tiene un espacio discursivo que habría que matizar. Es necesario advertir que en el poema la condición del yo narrativo es traspuesta en dos imágenes secundarias. La primera es el reflejo en la pantalla apagada de la cuchara entrando por la boca. Aquí se ha fraccionado la identidad del sujeto transformándose en el reflejo de una parte de sí mismo que se fuga y retrocede entre las sombras del cuarto. La segunda imagen de este yo vencido es aquélla en que, por transposición de un reflejo en la pantalla de televisión, aparece como un aviso comercial de sí mismo. En ambos gestos, el narrador se identifica específicamente como objeto junto a otro objeto de propaganda: la humilde sopa Campbell con que comparte este silencioso comercial. Estos argumentos muestran que la "caída" del narrador se expresa en un discurso muy específico, que es el discurso de la publicidad, en el cual el Yo es codificado como cosa. La vinculación del arte con el mundo cotidiano de los productos es frecuente no sólo en el arte Pop, sino que está presente en la producción cultural posmoderna en general. En el caso de la poesía de Óscar Hahn, esta vinculación no se limita a este poema ni es casual, sino que forma parte de un plan en su variada poética. Veámos la siguiente poesía, también de Mal de amor.

Sociedad de consumo

Caminamos de la mano por el supermercado entre las filas de cereales y detergentes

Avanzamos de estante en estante hasta llegar a los tarros de conserva

Examinamos el nuevo producto anunciado por la televisión

Y de pronto nos miramos a los ojos y nos sumimos el uno en el otro

y nos consumimos

Pocos poemas describen con tan eficiente brevedad un tema tan profundo como los males de la sociedad de consumo: la fetichización de la mercancía y la mediación de los objetos en la aprehensión de la realidad. En este poema, la relación humana, aun aquélla 
restringida a los actos más simples, como el mirarse y desearse en un supermercado, está mediada por los objetos de consumo. Las cosas, ya lo dijimos, son la malla lingüística en que emisor y receptor participan del discurso global. Hahn nos muestra, con su frecuente desenfado, cómo se va construyendo el discurso del consumo entre dos enamoradosmercancías, quienes, para ser consistentes con su discurso, se hallan frente a la única opción posible: la de consumirse el uno al otro.

Ahora hemos de regresar a la poética de Neruda. Atendamos a una sopa un tanto diferente: la descrita en "Oda al caldillo de congrio":

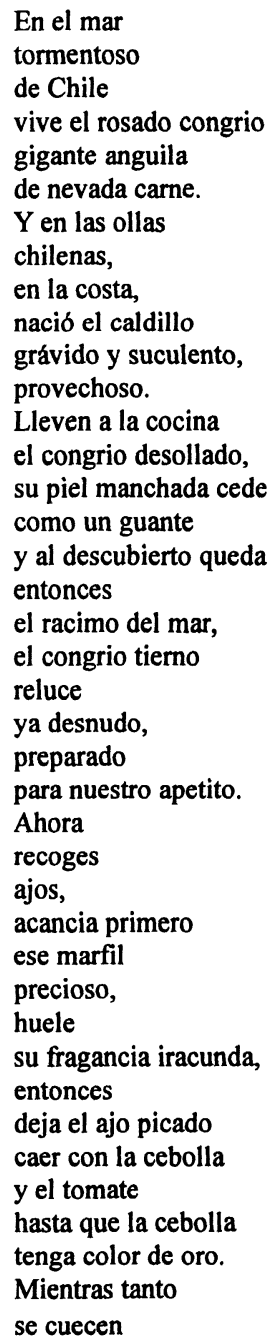

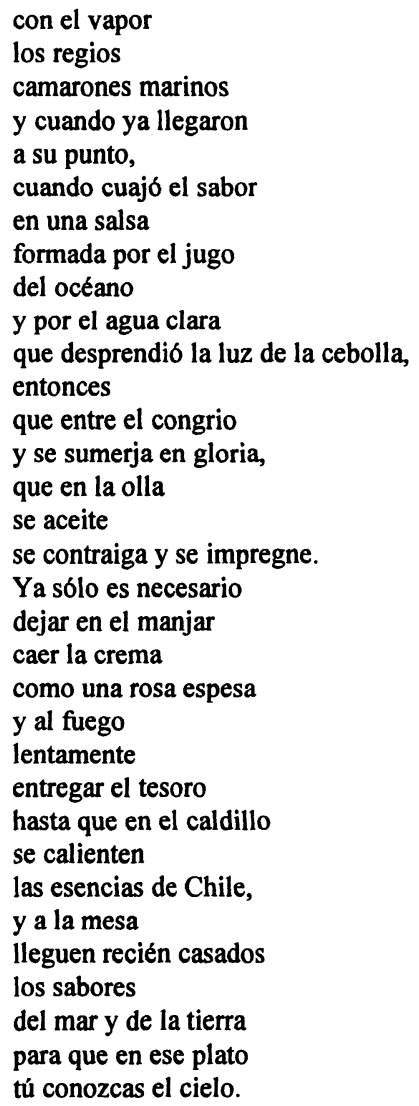


Sin duda, este caldo se aparta del ready made de las sopas comerciales. En realidad, desde el verso 13 en adelante la "Oda al caldillo de congrio" parodia el texto de una receta de cocina, dónde no falta el imperativo típico de esta narrativa: "lleven a la cocina", "recoges ajos", "deja el ajo picado", "que entre el congrio", etc. A diferencia de la sopa Campbell del poema de Hahn, que es un corolario de la soledad, este caldillo es la expresión del quehacer social. Es el resultado de una escritura pasada de mano en mano y de una práctica nacida de los vientres cálidos y humeantes de los fogones hogareños. En contraste con la sopa enlatada, que muestra la degradación de la naturaleza al ser rendida por el trabajo abstracto de la fábrica, el caldillo de la oda de Neruda muestra su irrevocable producción de uso. El caldillo de congrio no pertenece al mundo de las botellas de Coca Cola y los tarros de sopa Campbell del arte de Andy Warhol, expresiones éstas de un consumismo transnacional. El caldillo que Neruda ofrece servirnos, es una expresión de la realidad en que se produce. En la oda hay un énfasis toponímico de fronteras adentro: "el mar tormentoso de Chile", para "las ollas chilenas", que "nació" en la costa de Chile, es decir, hay un interés en relacionar la producción cultural -el caldillo-con la sociedad en que se gesta. Desde el verso 67, se nos informa además, que en él están las esencias de Chile. Se aprecia en este contraste con la obra de Warhol la gran tensión paradigmática que marca nuestro tiempo: el discurso de lo nacional frente al internacional. En otras palabras, se revela el proyecto de las economías locales que la era postindustrial intenta desmantelar en provecho de la economía global de las corporaciones - la economía de las ventajas relativas-y el "nuevo orden" que fuera inaugurado pública y oficialmente por Bush en cadena nacional de televisión a principios de los noventa.

\section{EL NUEVo EPISTEMA}

La poética de las cosas que Neruda presenta en las Odas ha ofrecido la oportunidad de estudiar - con la concurrencia de la sensibilidad tan contemporánea de Nicanor Parra y Óscar Hahn - un aspecto de la producción cultural que ha cambiado radicalmente en la época presente: la relación entre humanidad y naturaleza. Siguiendo una vieja forma de indagación, se ha propuesto en este trabajo que la continuidad entre la cosa y la mano que la produce - una relación que Engels encontraba consustancial a la naturaleza humanaes extremadamente productiva para establecer relaciones entre sociedad y las formas de producción cultural que de ésta emergen.

Es evidente que el mundo - incluso el tercer mundo- empieza obedecer a determinantes culturales distintas. Se ha producido un quiebre en el sistema epistemológico y tanto las formas del conocimiento como del arte van ofreciendo una homología con la nueva realidad. Para muchos, del modernismo va quedando la nostalgia sin historia por los eventos y personajes del pasado. Surge un sentimiento de pérdida por la caducación de las utopías y los modelos sociales de reivindicación humana. Para estos observadores, el futuro de Latinoamérica, su incorporación a una economía global controlada por las corporaciones transnacionales, conlleva una modificación sustancial de los modos de producción material y cultural del subcontinente. Además, sobre las áreas de la periferia se cierne el peligro adicional de la pérdida de identidad y de conciencia de las propias 
necesidades. "No terminamos aún de ser modernos - tanto esfuerzo que ha costado-y ya debemos ser posmodemos", ha dicho Ticio Escobar, reflejando este modo de pensar. ${ }^{12}$

Para otros, la posmodernidad no es ni negativa ni mucho menos reaccionaria, sino simplemente un tipo de relaciones sociales y de producción, tanto material como de formas de conciencia, cuya llegada era inevitable. La poesía siempre existirá, aunque sus códigos se construyan desde el lenguaje de las cosas, pero la pregunta que queda pendiente es: ¿encontraremos nuevos caminos o definitivamente nuestra existencia se volcará en la vida inconexa de los objetos?

${ }^{13}$ Ticio Escobar, "Posmodernismo/Precapitalismo", Casa de las Américas 168 (1988) 13-17. 
